\title{
Difficult Journey from Delivery to Discharge, Case of Congenital Diaphragmatic Hernia Karmacharya $\mathrm{RM}^{1}$, Dangol $\mathrm{S}^{2}$, Shrestha $\mathrm{M}^{3}$, Koju $\mathrm{R}^{1}$
}

\author{
${ }^{1}$ Department of Surgery \\ ${ }^{2}$ Department of Pediatrics \\ Kathmandu University Hospital, Dhulikhel hospital \\ Kavre, Nepal \\ ${ }^{3}$ Department of Sugery, \\ Kathmandu Model Hospital \\ Kathmandu, Nepal
}

Corresponding Author

Robin Man Karmacharya

Department of Surgery

Kathmandu University Hospital, Dhulikhel hospital

Kavre, Nepal

E-mail: reachrobin773@hotmail.com

\section{Citation}

Karmacharya RM, Dangol S, Shrestha M, Koju R. Difficult Journey from Delivery to Discharge, Case of Congenital Diaphragmatic Hernia. Kathmandu Univ Med J 2014;46(2):149-50.

\begin{abstract}
We report a case of congenital diaphragmatic hernia which was diagnosed prenatally for which surgical correction was done on second day of life. The child was discharged in 17 days and has resulted in good post repair condition of patient.

\section{KEY WORDS}

Bochdalek, congenital diaphragmatic hernia, hemithorax

\section{INTRODUCTION}

Congenital diaphragmatic hernia is an uncommon condition characterized by abnormal communication between abdominal and thoracic cavity with herniation of the abdominal contents caused by failure of closure of pleuroperitoneal canal.
\end{abstract}

\section{CASE REPORT}

Twenty five years primiparous lady at 40 weeks of gestation presented to antenatal clinic for regular antenatal check up with antenatal scan showing complex echogenic focus in left hemithorax with right sided mediastinal shift and normal right hemithorax. Previous ante natal scan however was normal. After 2 days of admission she underwent emergency caesarian section for cephalo-pelvic disproportion. The outcome was single live male baby with APGAR score of $6 / 10$ at birth. Child was immediately intubated, ventilated. Portable chest $x$ - ray showed bowel content in left hemi thorax with right sided mediastinal shift (Fig. 1). With this, diagnosis of congenital diaphragmatic hernia was confirmed.

Surgical repair was done at 36 hours of life with findings of small bowel, large bowel, spleen (except stomach) in left hemi thorax, posterior lip of diaphragm was absent (Bochdalek type). Contents were reduced and diaphragm edge was sutured to sixth rib. Post operative chest $\mathrm{x}$-ray showed expansion of lung with no bowel loops in hemi thorax (Fig. 2). Postoperatively the child developed necrotising enterocolitis which was managed conservatively. The child also developed pneumonia which was managed with broad spectrum antibiotics. The child was discharged on $17^{\text {th }}$ day. At 6 months, the child was perfectly normal, with good developmental milestones. There was no shortness of breath, difficulty feeding. The chest $x$-ray was normal. The patient was followed up every three months. In one year follow up, the patient is doing fine with developmental milestones coorelating with age. Chest $x$-ray at one year shows good expansion of both the lungs (Fig. 3). 


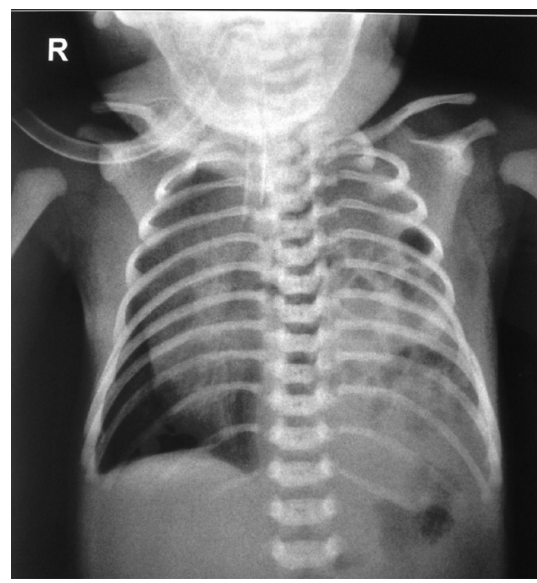

Figure 1. Preoperative Chest X-ray.

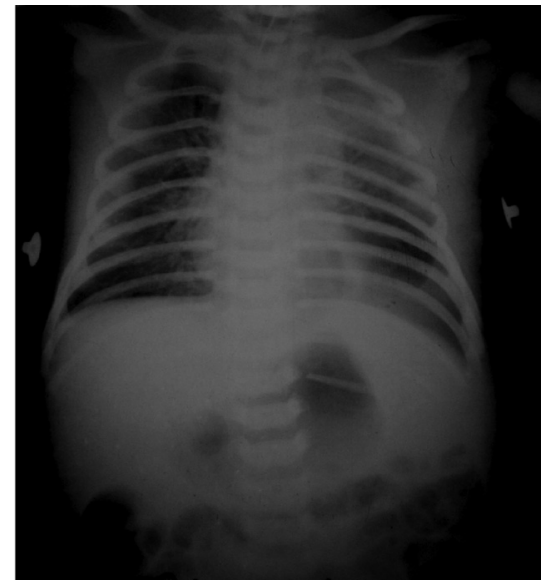

Figure 2. Postoperative Chest X-ray (Day 3)

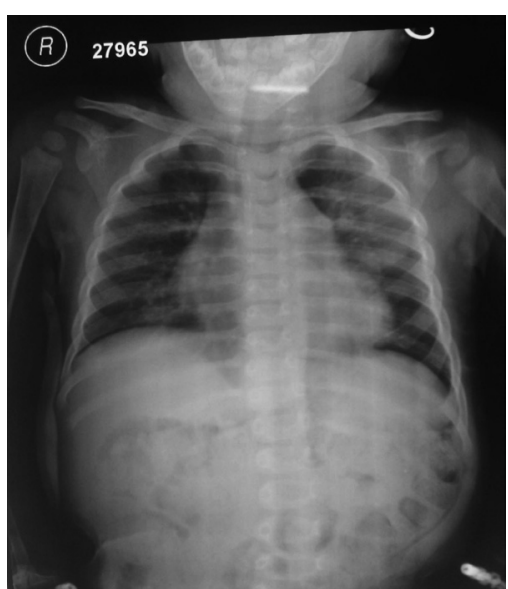

Figure 3. Preoperative Chest X-ray.

\section{DISCUSSION}

Congenital diaphragmatic hernia is an abnormal defect in the diaphragm with herniation of abdominal content into hemithorax. This condition is more common on the left side. ${ }^{1,2}$ Although the exact cause for this condition is unknown, sometimes it is associated with other syndromes, making genetic cause a likely possibility. ${ }^{3,4}$ The failure of closure of embryonic pleuroperitoneal canal is the major pathology. Ultrasonography is the main stay for diagnosis antenatally, while chest $\mathrm{x}$-ray is used for diagnosis postnatally. ${ }^{1,5}$ Its association with respiratory problems like pulmonary aplasia or hypoplesia causes significant morbidity and morbidity. ${ }^{6}$ Even in centers with good facility of appropriate surgical care, the mortality of this condition is $50 \% .{ }^{7}$ The condition occurs in about $1-5 / 10,000$ births. ${ }^{8}$ The respiratory distress in these patients is added by persistent pulmonary hypertension. ${ }^{9}$ The initial management is to stabilize the patient in the form of respiratory support in the form of mechanical ventilation with low tidal volume. Bag and mask ventilation however should not be done. High frequency oscillatory ventilation has found to be promising in these patients. ${ }^{10}$ Once the baby is stabilized, the surgical correction can be done. There still exists debate about

\section{REFERENCES}

1. Emeka B. KesiemeChinenye N. Kesieme : Congenital Diaphragmatic Hernia: Review of Current Concept in Surgical Management. ISRN Surg 2011, 2011: 1-8.

2. Clark RH, Hardin WD Jr, Hirschl RB et al. Current surgical management of congenital diaphragmatic hernia: a report from the Congenital Diaphragmatic Hernia Study Group. J Pediatr Surg 1998,33:1004-9

3. Zaiss I, Kehl S, Link K, et al. Associated Malformations in Congenital Diaphragmatic Hernia. Am J Perinatol 2011, 28:211-8.

4. McPherson EW, Ketterer DM, Salsburey DJ. Pallister-Killian and Fryns syndromes: nosology. Am J Med Genet 1993;47:241-5.

5. Nakayama DK, Harrison MR, Chinn DH, Callen PW, Filly RA, Golbus MS, et al. Prenatal diagnosis and natural history of the fetus with a congenital diaphragmatic hernia: initial clinical experience. J Pediatr Surg 1985, 20:118-124.

6. Mariusz Mielniczuk, Krzysztof Kusza, Piotr Brzeziński et al.Current guidelines on management of congenital diaphragmatic hernia. Anaesthesiology Intensive Therapy 2012, 44: 232-7. when the patient should be operated. It is believed that the postponement of surgical repair until vital functions particularly mean arterial pressure and oxygen saturation are stabilized significantly improves survival. ${ }^{6}$ Hence waiting at least $36-48$ hours is advocated. ${ }^{6}$ During surgical correction, a subcostal or transverse abdominal incision is made, herniated viscera carefully reduced and the diaphragmatic orifice is closed in interrupted sutures. The intercostal tube drainage is also not advocated due to high risk of injury and infection in hypoplastic lung. ${ }^{11}$ Sometime, for closure of huge defects, polytetrafluoroethylene (PTFE) patch are required to achieve tension-free repair. ${ }^{1,12}$

\section{CONCLUSION}

Diaphragmatic hernia thus is physiologic emergency and not a surgical emergency. Surgical repair at correct time can improve survival and help in lung expansion and growth in case of hypoplastic lung. Congenital diaphragmatic hernia is one of the most challenging problems in perinatal surgery. Survival of such case must have resulted from best interdepartmental cooperation, timely detection and proper intervention.

7. Stege G, Fenton A, Jaffray B. Nihilism in the 1990s: the true mortality of congenital diaphragmatic hernia. Pediatrics 2003, 112:532-5.

8. Gallot D, Boda C, Ughetto S, Perthus I et al. Prenatal detection and outcome of congenital diaphragmatic hernia: a French registry based study. Ultrasound Obstet Gynecol 2007, 29:276-283

9. Keijzer R, Puri P. Congenital diaphragmatic hernia. Semin Pediatr Surg 2010, 19:180-5.

10. Karl SR, Ballantine TV, Snider MT: High-frequency ventilation at rates of 375 to 1800 cycles per minute in four neonates with congenital diaphragmatic hernia. J Pediatr Surg 1983, 18:822-828.

11. Reiss I, Schaible T, van den Hout $L$ et al. Standardized postnatal management of infants with congenital diaphragmatic hernia in Europe: the CDH EURO Consortium consensus. Neonatology 2010;98: 354-64.

12. Grethel EJ, Cortes RA, Wagner AJ et al. Prosthetic patches for congenitaldiaphragmatic hernia repair: Surgisis vs Gore-Tex. J Pediatr Surg 2006,41:29-33. 